\title{
A importância de Julius Kaiser para a Organização do Conhecimento: um estudo comparativo com as perspectivas de Cutter, Otlet e Ranganathan
}

\author{
The importance of Julius Kaiser to the Knowledge Organization: a comparative study with \\ Cutter, Otlet and Ranganathan approaches
}

\begin{abstract}
Rodrigo de Sales
Doutor em Ciência da Informação pela Universidade Estadual Paulista - UNESP, campus de Marília. Docente do Departamento de Ciência da Informação da Universidade Federal Fluminense e Coordenador do Programa de Pós-Graduação em Ciência da Informação - PPGCI/UFF.

E-mail: rodrigo.sales.s@gmail.com

José Augusto Chaves Guimarães Livre-docente em Análise documentária pela Universidade Estadual Paulista. Professor Titular do Departamento de Ciência da Informação da Universidade Estadual Paulista Júlio de Mesquita Filho - UNESP, campus de Marília. E-mail: guima@marilia.unesp.br
\end{abstract}

\section{Resumo}

A indexação sistemática elaborada por Julius Kaiser em princípios do século XX, embora não tenha alcançado merecido destaque nos cursos e na literatura de Biblioteconomia e Ciência da Informação, ao definir a análise e a síntese de assuntos especializados com base no princípio de categorização, fincou bases fundamentais para o quadro teórico e metodológico da organização do conhecimento. O presente artigo, por meio de em exercício reflexivo, cotejou a forma de organização do conhecimento elaborada por Kaiser com princípios e métodos desenvolvidos por alguns de seus contemporâneos, como Cutter, Otlet e Ranganathan. Revelaram-se interlocuções teóricas e metodológicas que fundamentalmente colocam Kaiser no rol dos desenvolvedores centrais do campo epistemológico da organização do conhecimento.

Palavras-chave: Organização do conhecimento. Indexação. Método analítico-sintético. Julius Kaiser. Cutter. Otlet. Ranganathan.

\begin{abstract}
Although the systematic indexing created by Julius Kaiser at the beginning of the $20^{\text {th }}$ century has not yet reached its due prominence in Library and Information Science courses and literature, it set the fundamental basis for the theoretical and methodological framework of knowledge organization by defining the analysis and synthesis of specialized subjects based on the principle of categorization. Through a reflective exercise, this study aims to compare the form of knowledge organization proposed by Kaiser with the principles and methods developed by some of his contemporaneous fellow academics, such as Cutter, Otlet and Ranganathan. The outcome was theoretical and methodological dialogues that fundamentally place Kaiser in the roll of central developers in the epistemological field of knowledge organization.
\end{abstract}

Keywords: Knowledge Organization. Indexing. Analytic-synthetic method. Julius Kaiser. Cutter. Otlet. Ranganathan. 
A importância de Julius Kaiser para a Organização do Conhecimento: um estudo comparativo com as perspectivas de Cutter, Otlet e Ranganathan

\section{Introdução}

O trabalho desenvolvido pelo bibliotecário alemão, naturalizado norteamerico, Julius Otto Kaiser (1968-1927), superficialmente abordado nos compêndios da Ciência da Informação das décadas de 1960 e 1970, começou a ganhar merecida atenção nos estudos de Coates (1988), Svenonius (2000), Dousa (2010a; 2010b) e Sales (2012; 2014). A relevância de Julius Kaiser para o quadro teórico e metodológico da organização do conhecimento será aqui abordada com base nas contribuições advindas da indexação sistemática desenvolvida por Kaiser em princípios do século XX. Duas foram as obras publicadas pelo autor para divulgar seu sistema de indexação: The Card System at the Office (1908) e Systematic Indexing (1911). Segundo o próprio Kaiser (1911), o leitor deve entender ambos os livros como duas partes de uma mesma obra, em que a primeira se contextualiza todos os aspectos que envolvem o tratamento de documentos de escritórios por meio do sistema de cartões bibliográficos e a segunda apresenta detalhadamente o sistema de indexação elaborado para ambientes especializados.

Atuando profissionalmente em unidades de informação de instituições especializadas no Reino Unido e nos Estados Unidos, ao longo de aproximadamente três décadas Kaiser esteve envolvido com a especificidade de documentos empresariais e de escritório. Dada a particularidade de tais documentos, Kaiser desenvolveu uma forma sistemática de indexação, denominada systematic indexing, baseada no princípio teórico da categorização, que serviria tanto para a análise quanto para a síntese dos assuntos especializados.

O propósito deste artigo é mostrar que ao elaborar sua indexação sistemática Kaiser contribuiu fundamentalmente para questões centrais da organização do conhecimento, manifestadas tanto na catalogação de assuntos quanto na classificação e na indexação. Para tanto, definiu-se como objetivo principal relacionar o trabalho desenvolvido por Kaiser com trabalhos desenvolvidos por alguns de seus contemporâneos, consagrados como referenciais teóricos e metodológicos na área da organização do conhecimento. Assim, do ponto de vista metodológico, o estudo aqui apresentado se caracteriza como um exercício comparativo e reflexivo voltado ao campo epistemológico da organização do conhecimento, especificamente à catalogação de assuntos, à classificação bibliográfica e à indexação. O que se revelam são interlocuções que aproximam fundamentalmente Kaiser de C. A. Cutter (na definição de regras), de P. Otlet (na análise da informação) e S. R. Ranganathan (no movimento analíticosintético).

InCID: R. Ci. Inf. e Doc., Ribeirão Preto, v. 7, n. 1, p. 43-65, mar./ago. 2016. 


\section{Kaiser e Cutter: a definição de princípios e regras}

Criador das primeiras regras para construção de catálogos alfabéticos de assunto, Charles Ammi Cutter (1837-1903) é nome central na linha de estudos conhecida como Catalogação de Assunto, inserida no universo investigativo da organização temática da informação. Como destaca Barbosa (1969), a imortalização de Cutter para o universo biblioteconômico deu-se por meio da obra Rules for a Dictionary Catalog (primeira edição publicada em 1876) e da Tabela de Autores de Cutter. Em 1868, Cutter foi nomeado bibliotecário do Boston Athenaeum, onde elaborou o catálogo púbico da instituição entre 1874 e 1882. Cutter foi membro fundador da American Library Association (ALA), editor da publicação Library Jornal (da mesma instituição) e criador das regras que culminaram no surgimento do catálogo dicionário. Vale destacar que Cutter elaborou, também, a chamada Expansive Classification, publicada entre 1891 e 1893, que iria influenciar o desenvolvimento da Classificação da Library of Congress, sobretudo na definição das classes principais (MILLS, 1960; BARBOSA, 1969; FOSKETT, 1973; MALTBY, 1975; PIEDADE, 1977; COATES, 1988).

No entanto, a grande contribuição de Cutter para o campo da organização do conhecimento, notadamente no que se refere à organização temática da informação, foram suas regras definidas na obra Rules for a Dictionary Catalog (BARBOSA, 1969; FOSKETT, 1973; MALTBY, 1975; PIEDADE, 1977; COATES, 1988). A obra de Cutter recebeu esse nome porque, como explica o próprio autor, “os cabeçalhos (autor, título, assunto e forma) são organizados como as palavras em um dicionário, em ordem alfabética" (CUTTER, 1904, p. 19. Tradução livre). A catalogação de assuntos se ocupa com a representação do conteúdo temático dos documentos com o objetivo de gerar o ponto de acesso de determinado assunto. Autores como Shera e Egan (1969), Teixeira (1979), Mey (1987) e Taylor (1995) enfatizam que a localização de documentos por meio de pontos de acesso por assunto é o tipo de busca mais utilizado pelos usuários de bibliotecas. Definindo a catalogação nesse viés operacional, Immroth (1971) afirma que a catalogação por assunto consiste em classificar documentos segundo um sistema próprio e definir cabeçalhos de assunto segundo uma dada lista de autoridade. É particularmente na catalogação de assuntos que o trabalho realizado por Cutter impacta no quadro teórico-metodológico da organização do conhecimento.

No período anterior às regras de catalogação publicadas por Cutter o que se tinha eram diversos conjuntos de regras que não tentaram as estabelecer de um modo sistemático e, com 
A importância de Julius Kaiser para a Organização do Conhecimento: um estudo comparativo com as perspectivas de Cutter, Otlet e Ranganathan

isso, descomprometidos com a investigação do que poderiam ser os princípios fundamentais da catalogação. Quando Cutter publicou as Rules for a Dictionary Catalog o universo da catalogação ganhou nova substancialidade, passou efetivamente a ser tratado como um campo fértil de pesquisa (BARBOSA, 1969; FOSKETT, 1973; PIEDADE, 1977) marcado por um caráter pragmático voltado ao usuário (MEY, 1987). As regras de Cutter estão divididas em duas grandes partes, a primeira dedicada à Entrada (Onde entrar) e a segunda dedicada ao Estilo (Como entrar). Para Cutter (1904), a importância de decidir corretamente a entrada de um assunto, quando da realização da catalogação, se deve ao fato de que se não houver um princípio óbvio para orientar o catalogador não haverá o porquê de o público usuário acreditar que encontrará o que necessita usando um termo de entrada em detrimento de outro. E o maior benefício da existência de tal princípio é, para Cutter (1904), a probabilidade de uma convergência nas decisões tomadas por diferentes catalogadores no momento da elaboração e escolhas dos cabeçalhos.

As regras de Cutter para a elaboração dos cabeçalhos eram fundamentadas em três princípios básicos:

1. princípio específico - Os assuntos devem dar entrada pelo termo mais específico e não pela classe a que está subordinado (CESARINO; PINTO, 1978, p. 274) 2. princípio de uso - os cabeçalhos serão aqueles sob os quais é provável que a maioria dos americanos educados irão procurar, com referências cruzadas para outras formas de cabeçalhos relacionados. É o princípio da conveniência, de acordo com a necessidade dos usuários (CESARINO; PINTO, 1978, p. 275)

3. princípio sindético - Cutter propôs o desenvolvimento nas listas de cabeçalhos de assunto de estruturas sindéticas que, através de uma rede bem construída de referências cruzadas, poderiam ajudar ou mesmo superar este problema (CESARINO; PINTO, 1978, p. 275).

A importância dos princípios de Cutter aparece, pelo menos, nas obras de Mills (1960), Foskett (1973), Langridge (1973) e Coates (1988). Coates (1988), que faz análise mais apurada a respeito da fundamentação do catálogo dicionário (analisando também catálogos posteriores ao de Cutter), faz uso dos princípios e das regras de Cutter para tecer suas concepções a respeito de alternativas para entradas de termos específicos, ordem dos cabeçalhos compostos e uniformidade das regras em relação ao uso costumeiro dos assuntos. As regras de Cutter apresentavam algumas fragilidades como a) a aceitação de que a linguagem natural fosse o único tipo de terminologia possível e b) a opção de colocar o termo mais significativo como termo de entrada, isso relegava ao catalogador o julgamento do que era mais ou menos significativo (FOSKETT, 1973). Porém, a proposta de que o termo de entrada seja escolhido levando em consideração a área de conhecimento onde ocorre a catalogação, a preocupação com a quantidade de assuntos atribuídos, podendo esses serem substituídos por remissivas 
Rodrigo de Sales e José Augusto Chaves Guimarães

(MEY, 1995), mostra mais uma vez o pioneirismo do trabalho de Cutter em se tratando de aspectos recorrentes nos estudos posteriormente realizados pelos pensadores da classificação e indexação de assuntos. Todos esses pontos, aqui ressaltados como pioneiros no âmbito da organização da informação por assuntos, são posteriormente trabalhados por Kaiser em sua indexação sistemática.

Kaiser, a exemplo do que fez Cutter para a construção de cabeçalhos de assuntos, definiu regras para a formação dos enunciados de assuntos. Ao todo são seis regras estabelecidas com o objetivo de obter êxito no processo de indexação, e consequentemente no processo de recuperação da informação. A saber:

1) Selecione o que é realmente importante para seu objetivo sem considerar forma ou extensão;

2) Concentre-se na informação relativamente específica;

3) Lide com cada item independentemente;

4) Não adultere o nome dos concretos;

5) Evite inversão, preposições e plurais sempre que possível;

6) Teste a exatidão de cada enunciado pelo ponto de vista tanto do indexador quanto do usuário. (KAISER, 1911, § 348 - Tradução livre)

Conforme observado por Sales (2012; 2014) e por Sales e Guimarães (2014), Kaiser se assemelha a Cutter não somente na iniciativa de estabelecer regras para a formação de termos de indexação, mas notadamente nos focos abordados. O princípio específico de Cutter, mesmo questionado por Kaiser - o quão específico é o específico? - é abordado nas regras de formação dos enunciados. Enquanto Cutter definia que os assuntos deviam dar entrada pelo termo mais específico e não pela classe a que está subordinado, Kaiser estabelecia que o foco devesse ser a informação relativamente específica. Embora ambos tenham se preocupado com a questão da especificidade do termo de representação de assuntos, Kaiser avançou a questão prevendo a necessidade que havia de possibilitar referências de assuntos específicos para os assuntos gerais, inexistente no catálogo dicionário de Cutter (FOSKETT, 1986). Como afirma Foskett (1973), Cutter apresentava razões mais econômicas, não teóricas, e “é lamentável que a maioria das bibliotecas que adotam a abordagem alfabética restrinja, de fato, as remissivas ao tipo descendente" (FOSKETT, 1973, p. 50). Segundo o autor, a ligação dos termos (concretos) em redes de remissivas coordenadas de forma superordenada e subordinada, prevista no sistema de Kaiser, era o mais adequado. Mills (1960) explica que os termos eram relacionados na rede de remissivas de Kaiser por meio de cartões guias que especificavam, além das relações de termos superordenados e subordinados, também termos sinônimos e qualquer outro termo/concreto que apresentasse alguma conexão encontrada no momento da indexação da coleção.

InCID: R. Ci. Inf. e Doc., Ribeirão Preto, v. 7, n. 1, p. 43-65, mar./ago. 2016. 
A importância de Julius Kaiser para a Organização do Conhecimento: um estudo comparativo com as perspectivas de Cutter, Otlet e Ranganathan

Nota-se que essas relações entre termos tecidas no systematic indexing é uma continuidade do princípio sindético preconizado por Cutter. Observa-se que essa atenção dada aos tipos de relacionamento entre os termos, iniciada no catálogo dicionário de Cutter por meio das referências cruzadas e avançada no sistema de Kaiser por meio das redes de remissivas, é o início de uma preocupação que permeia os estudos de organização do conhecimento desenvolvidos posteriormente por Ranganathan e seus seguidores da corrente inglesa de indexação. Kaiser se ocupa também com a questão apresentada no princípio de uso de Cutter. Ambos os sistemas estão voltados não apenas para o êxito da representação (catalogação e indexação), mas principalmente para a satisfação das necessidades dos usuários. E nesse ponto, mais uma vez é possível verificar um avanço de Kaiser com relação ao trabalho iniciado por Cutter. Enquanto este apresentava uma postura mais dedutiva, pontuando que o cabeçalho deveria ser escolhido de acordo com a dedução de quais os termos seriam provavelmente relacionados pelo usuário no momento da busca, Kaiser buscava extrair do próprio usuário a exatidão dos enunciados. Embora se saiba que a representação de assuntos não se trata de uma tarefa isenta de subjetividades, nota-se que tanto Cutter quanto Kaiser buscaram minimizar esse fator ao determinarem princípios e regras que proporcionassem uma padronização mínima e necessária para o fazer da catalogação e da indexação (SALES, 2012; 2014; SALES; GUIMARÃES, 2014).

Porém, é possível verificar que tanto o princípio de uso de Cutter quanto as Regras 2 e 3 de Kaiser dão vazão às subjetividades dos catalogadores e indexadores. Cutter determinou que os usos dos termos empregados nos cabeçalhos deviam seguir o princípio da conveniência, de acordo com a necessidade dos usuários, fator que delega a cada catalogador o julgamento do que seria mais ou menos conveniente aos usuários. Da mesma forma, Kaiser definiu que os termos a serem empregados nos enunciados deveriam ser os mais específicos (Regra 2), o que dá margem à subjetividade de cada indexador decidir o que de fato é mais específico e, tratados de maneira independente (Regra 3), fato que seria prejudicial ao se entender que, na realidade, o significado dos termos se relacionam com os contextos e com a ótica de quem cria e de quem utiliza índices. Desse modo, é preferível entender os princípios de Cutter e as regras de Kaiser não como tentativas insuficientes de se neutralizar os aspectos que não sejam padronizáveis, mas sim como esforços iniciais em prol de uma uniformidade nos fazeres atinentes à catalogação e à indexação, consistindo nos pilares iniciais, para a construção de declarações verbais de assuntos, do quadro evolutivo da organização temática da informação. 
Rodrigo de Sales e José Augusto Chaves Guimarães

O sistema baseado em categorias de Kaiser era suficiente dentro de certos limites e insuficiente para lidar com a bibliografia moderna (FOSKETT, 1973), haja vista que sua concepção muito prática e simplista não contemplava maiores regras para situações específicas (TURNER apud STRAIOTO; GUIMARÃES, 2004). Porém, como afirma Rodriguez (1984), a simplicidade de suas regras de concretos e processos fazem o sistema de Kaiser atrativo ainda hoje. Segundo Foskett (1986), Kaiser conseguiu levar ao arranjo alfabético a lógica classificatória, e sua divisão de assuntos por duas grandes categorias é teorema fundamental para a organização de assuntos. A importância do trabalho de Kaiser reside em pontos fundamentais da pesquisa de organização e representação do conhecimento, ele se aproximou mais da solução de problemas básicos da indexação do que qualquer outro antes (METCALFE, 1959), como por exemplo, a solução do problema na ordem de importância (FOSKETT, 1973). Conseguiu contemplar as dimensões estáticas (concretos) e dinâmicas (processos) do conteúdo de um documento (STRAIOTO; GUIMARÃES, 2004) e, sobretudo, lançou os princípios de facetagem (CESARINO; PINTO, 1978; RODRÍGUEZ, 1984; STRAIOTO; GUIMARÃES, 2004; DOUSA, 2010b).

\section{Kaiser e Otlet: a análise da informação}

Paul Otlet (1868-1944) tem seu nome gravado no universo da organização do conhecimento por inúmeros motivos, dos quais, opta-se em destacar aqueles relativos à elaboração do Repertório Universal Bibliográfico desenvolvido no Instituto Internacional de Bibliografia (IIB) na virada do século XIX para o século XX. Em 1905, o Repertório do IIB, que consistia em um catálogo de arranjo sistemático, foi publicado sob a denominação de Manuel du Répertoire Universel Bibliografique e passou a ser denominado Classificação Decimal Universal (CDU) a partir de sua segunda edição (1927-1933). A CDU seguramente consistia no principal trabalho desenvolvido pela equipe do IIB.

É justamente neste contexto que Otlet elabora sua forma de análise da informação, pautada na ideia de que a representação dos conhecimentos veiculados pelos documentos poderia ser realizada não somente pela decomposição de unidades bibliográficas menores (como artigos dentro de periódicos ou capítulos dentro de livros), mas, principalmente, pela análise de unidades de informação menores, tais como os conceitos, os fatos e evidências encontrados dentro dos textos. Neste aspecto, Dousa (2010b) e Sales $(2012 ; 2014)$ aproximam teoricamente os trabalhos e pensamentos de Kaiser e Otlet. As unidades de informação 
A importância de Julius Kaiser para a Organização do Conhecimento: um estudo comparativo com as perspectivas de Cutter, Otlet e Ranganathan

(conceitos e fatos), depois de identificadas, poderiam ser reconfiguradas em um novo arranjo com o propósito de facilitar a recuperação dos documentos (DOUSA, 2010 b), e isso é notório nos trabalhos tanto de Otlet quanto de Kaiser.

Porém, antes de aproximar os pensamentos de Kaiser e Otlet, faz-se necessário ponderar as diferenças existentes entre ambas as perspectivas. Verifica-se, com base em Dousa (2010 b), que as diferenças entre ambos residem essencialmente na estrutura de organização do conhecimento - ordem classificatória versus ordem alfabética - e no escopo da estrutura universalismo versus localismo. Enquanto Otlet sustentava preferência à ordem classificatória dos assuntos, como presente na CDU, por acreditar que a ordem alfabética dava vazão à subjetividade do indexador na escolha das palavras (termos) a serem utilizadas nos índices, Kaiser desenvolveu seu método de tal forma que os assuntos fossem ordenados alfabeticamente. Porém, diferentemente dos métodos alfabéticos tradicionais, que não permitiam aproximações semânticas entre os assuntos indexados, Kaiser buscou resolver essa questão com o emprego de cartões guias, isto é, para cada termo de entrada do índice seria elaborado um cartão guia que serviria como remissiva para outros termos de entrada que guardassem alguma relação semântica com o termo em questão. Esse dispositivo de referências cruzadas permitia que, mesmo diante de uma ordenação alfabética, os usuários tivessem acesso às informações relacionadas tematicamente. Portanto, a ordenação do índice, ou seja, a estrutura da organização do conhecimento era um ponto em que Otlet e Kaiser notoriamente divergiam (DOUSA 2010 b; SALES, 2012; 2014).

Outra diferença flagrante no pensamento de ambos diz respeito ao escopo do índice. Otlet se ocupava com os assuntos em uma dimensão universal, enciclopédica, assim como os classificacionistas de sua época. Por outro lado, bibliotecário especializado em unidades de informação de negócios, como empresas, indústrias, museus e bibliotecas especializados, Kaiser visava dar conta da organização sistemática dos conhecimentos específicos (especializados) veiculados por uma literatura técnica e profissional (DOUSA, 2010b). Esse foco em desenvolvimento de índices para organizações particulares (localismo), pautado em literaturas e conhecimentos especializados, distinguia Kaiser não apenas de Otlet, mas também de seus demais contemporâneos, como Dewey, Cutter, Brown e Ranganathan. Porém, essa diferença de escopo entre os sistemas de Kaiser e de Otlet não parece ser necessariamente fruto de uma divergência de pensamentos, mas sim uma determinação conjuntural, uma vez que o caráter especializado de Kaiser o levou a preocupações de ordem especializada, ao passo que, 
a visão universalizante de Otlet, despertava um interesse mais enciclopédico (SALES, 2012; SALES; GUIMARÃRES, 2014).

Salvaguardadas as diferenças nas concepções de Kaiser e Otlet, verifica-se o ponto que efetivamente pode ser considerado uma interseção teórica entre ambos - a análise da informação por meio das partes (unidades de informação) do conteúdo. A aproximação teórica de Otlet e Kaiser está, sobretudo, no fato de ambos se descolarem da organização pautada nos documentos visando à organização dos conhecimentos neles contidos. Para Otlet, conhecimento engloba tudo aquilo que se conhece a respeito dos objetos do mundo externo ou do próprio pensamento, sejam eles objetos físicos (naturais ou artificiais) ou não-físicos (leis, pensamentos, sentimentos etc.). Os elementos primários (principais) desses objetos são os "fatos" ou "ideias", que, estruturados conceitualmente pelos autores, são registrados nos documentos, de modo a refletir a visão que cada autor tem a respeito dos fenômenos apresentados e discutidos (DOUSA, 2010b). Na concepção de Kaiser, o conhecimento, que é o resultado da observação e do pensamento que se tem a respeito de algo, está materializado na literatura especializada, e pode ser mais bem compreendido por meio da análise das categorias concreto (entidade), país (lugar) e processo (ação). É curioso perceber que já no início do Século $\mathrm{XX}$, tanto Otlet quanto Kaiser, estavam atentos ao fato de que os usuários/leitores/pesquisadores/profissionais buscavam, efetivamente, informações, fatos e ideias que propiciassem algum tipo de conhecimento. É perceptível que tanto um quanto o outro afirmavam ser necessário dissociar a informação do documento e analisar os elementos que compunham a informação, a fim de mais bem organizar o conhecimento e, consequentemente, proporcionar uma recuperação de informação mais específica (SALES, 2012; 2014).

Além de concordarem que os assuntos deveriam ser organizados com base na análise da informação contida nos documentos, Otlet e Kaiser convergem também nas formas de alcançarem tal organização. Para Otlet, a função do documentalista era extrair dos documentos os componentes informativos relevantes (unidades de informações), separando-os do contexto bibliográfico original e registrando-os individualmente, possibilitando que tais registros fossem estabelecidos analiticamente em repertórios enciclopédicos, que, por sua vez, propiciariam a interligação entre unidades de informação e publicações diversas (DOUSA, 2010b). Para Kaiser, a função do indexador era virtualmente a mesma. O indexador deveria analisar a literatura indexável de modo a extrair dela os componentes informativos (informações indexáveis), separando-os da literatura, registrando-os em enunciados de assuntos que 
A importância de Julius Kaiser para a Organização do Conhecimento: um estudo comparativo com as perspectivas de Cutter, Otlet e Ranganathan

comporiam um índice sistemático, que viabilizaria, por sua vez, a interligação entre declarações de assuntos e documentos diversos.

Nesse sentido, é possível afirmar que o universo da organização temática da informação tomou contato com uma nova perspectiva a partir dos trabalhos de Otlet (na documentação) e de Kaiser (na indexação), uma perspectiva que estabelece a organização de assuntos baseada na análise de seus componentes informativos. Ou melhor, uma organização não mais de documentos, mas, sim, de informações a respeito de conhecimentos. Como afirma Dousa (2010b), tanto o índice sistemático de Kaiser quanto os repertórios enciclopédicos de Otlet foram desenvolvidos para proporcionar o acesso imediato à informação. Assim como é possível afirmar uma interseção teórica na análise da informação (análise das unidades menores de informação) desenvolvida por Otlet e Kaiser, é observável, também, a semelhança que ambos tiveram no que se refere à viabilização tecnológica de seus sistemas.

Tanto Otlet quanto Kaiser adotaram o sistema de cartões padronizados. Ao final do Século XIX e início do Século XX, tal tecnologia figurava como "modernista" e, avançava diversas questões práticas de relacionamento entre registros e documentos, se comparado aos sistemas de livros de registro, comuns até então. Um sistema baseado em cartões uniformemente dimensionados contidos de transcrições padronizadas de informações, alocados fisicamente em gavetas (fichários), relacionados com mobiliários específicos e organizados conceitualmente por um esquema de classificação, era realmente avançado e eficiente na época de Otlet e Kaiser. Visto que, no referido sistema, "cada cartão consiste no registro da unidade que representa um item de informação" (FLANZREICH apud DOUSA, 2010b, p. 21), os cartões figuram como recursos ideais para registrarem o resultado das análises de informações. Cada cartão deveria servir como o portador de uma única unidade de informação extraída de um dado documento, estabelecendo uma relação um-para-um que corresponderia à ligação entre cartão e unidade de informação (componente informativo extraído do conteúdo do documento). Otlet chamou esse princípio de "princípio monográfico", ao passo que Kaiser o denominou "referência individual" (SALES, 2014).

Vislumbrando a possibilidade de diferentes cartões possuírem informações referentes ao mesmo assunto, Otlet e Kaiser trabalharam distinções de cartões por meio de cores, tamanhos e cartões guias, que possibilitassem "referências cruzadas" de assuntos relacionados. Assim, o índice de cartões representaria tanto os componentes individuais da informação quanto a estrutura em que tal informação está reunida (DOUSA, 2010b). A pertinência do sistema de 
cartões para os propósitos de organização do conhecimento de Otlet e Kaiser é enfatizada por Dousa na seguinte afirmação

In Otlet's and Kaiser's eyes, then, the card system was an ideal mechanism for gathering together information units gleaned from many different documentary sources, organizing them according to their intellectual content and guiding users to cards containing information on the particular subject of their concern (2010b, p, 22).

Kaiser, ao desenvolver seu sistema de indexação sistemática, aproximou-se das ideias de Otlet no que se refere à análise da informação por meio de seus elementos constituintes, deslocando-se de uma organização de documentos para uma organização de conhecimentos e, no que se refere também à viabilização tecnológica de tal organização, implementável por meio do sistema de cartões.

\section{Kaiser e Ranganathan: o movimento analítico-sintético}

O universo da organização temática da informação se transformou definitivamente a partir da década de 1930, com a consolidação da considerada era da facetagem, liderada pelo bibliotecário indiano Shiyali Ramamrita Ranganathan, criador da Colon Classification e da Teoria da Classificação Facetada. Nascido em 1892 na cidade de Shiyali, estado de Madras, e falecido em 1972 em Bangalore, ambas na Índia, Ranganathan obteve formação em Matemática passando por duas instituições indianas, a Hindu High School, em Shiyali, e o Christian College da Universidade de Madras, onde se tornou mestre em Matemática no ano de 1916. A transição de Ranganathan da Matemática para a Biblioteconomia é iniciada em 1924 quando da sua candidatura ao cargo de bibliotecário da Universidade de Madras. O cargo almejado por ele lhe foi concedido sob a condição de estudar Biblioteconomia em Londres, cidade onde passou cerca de um ano, primeiro estagiando no British Museum e depois estudando na School of Librarianship da London University.

A interlocução teórico-metodológica entre Kaiser e Ranganathan é aqui mostrada a partir do desenvolvimento do método analítico-sintético. Para tanto, foram definidos quatro pontos de observação que permitem a compreensão do método analítico-sintético em sua completude: a) os componentes da análise, b) a realização da análise, c) a realização da síntese e, d) o produto da síntese. A apresentação do exercício reflexivo que embasa essa argumentação se inicia pela dimensão analítica definida tanto por Kaiser quanto por Ranganathan. 
A importância de Julius Kaiser para a Organização do Conhecimento: um estudo comparativo com as perspectivas de Cutter, Otlet e Ranganathan

\section{As dimensões analíticas de Kaiser e Ranganathan}

Ao dissertar a respeito da dimensão analítica em Kaiser, é necessário retomar a noção exata do universo que o bibliotecário alemão se propôs a analisar. O universo a ser analisado por Kaiser é a literatura especializada, mais especificamente, a business literature - literatura veiculada no curso de qualquer negócio (comercial, técnico ou profissional). Kaiser entende por literatura o registro descritivo do que se observa e se raciocina a respeito de algo. É o resultado da observação das coisas e da tradução dessa observação em uma dada língua. Portanto, a literatura, enquanto materialização da observação humana, é constituída por registros que funcionam como representantes de conhecimentos e como fornecedores de informações. Tais registros, nesse contexto, estão materializados nos documentos. Desse modo, os registros fixados pela literatura especializada são representantes de conhecimentos especializados, materializados, por sua vez, em documentos de caráter específico. Se analisar, numa concepção aristotélica, consiste em decompor uma coisa composta em seus elementos mais simples e, numa perspectiva cartesiana, consiste em decompor um todo em suas partes, analisar a literatura especializada (indexável) é, portanto, tratá-la com base em seus elementos constituintes, ou seja, com base nos representantes de conhecimentos ali registrados. A perspectiva a partir da qual a literatura é analisada por Kaiser não é nem gramatical (baseada nos vários tipos de palavras, suas relações, seus usos e combinações) nem lógica (baseada nas várias formas de raciocínio). É uma perspectiva baseada no conhecimento e na informação transmitidos pela linguagem escrita nos documentos (KAISER 1908; 1911). Analisar sob essa perspectiva é, portanto, decompor a literatura especializada em seus elementos (registros) fundamentais, fornecedores de conhecimento e/ou informação. Assim, intencionalmente ou não, Kaiser se valeu da noção aristotélica de categorização.

Para nortear a identificação dos elementos informativos fundamentais presentes na literatura, concepção também de Otlet, Kaiser, diferentemente daquele, propõe a categorização dos discursos, a categorização dos assuntos veiculados pela literatura. Categorias, para Kaiser (1908, 1911), são as partes de um discurso registrado que revelam os elementos de conhecimento de um assunto em sua dimensão estática (concreto) e dinâmica (processo). Para analisar um assunto de um documento é necessário identificar em seu conteúdo os registros de conhecimento que correspondem aos concretos e os registros que dizem respeito às condições inerentes aos concretos, isto é, aos processos. Cabe, assim, ao indexador definir quando um registro da literatura corresponde a uma informação indexável do assunto, em outras palavras,

InCID: R. Ci. Inf. e Doc., Ribeirão Preto, v. 7, n. 1, p. 43-65, mar./ago. 2016. 
é função do indexador identificar no conteúdo dos documentos quais são os possíveis concretos e processos, inerentes ao assunto que está sendo indexado, que poderão servir pertinentemente à indexação.

A análise dos assuntos é realizada com base nos nomes das coisas (entes) e com base naquilo que é dito sobre as coisas, semelhante à análise das proposições definidas por Aristóteles. Porém, diferentemente de Aristóteles, cujo objetivo se assentava na descrição do mundo dos seres sensíveis por meio de dez categorias fundamentais, das quais nove dessas categorias serviriam como predicados da categoria principal (a substância), Kaiser trabalhou com apenas uma categoria (processo) para dar conta de identificar os aspectos que diziam respeito à sua categoria fundamental (concreto) (SALES, 2012; 2014; SALES; GUIMARÃES, 2014). Por definição, apresentam-se as categorias de Kaiser: concretos - são os terms commodities, as coisas, os produtos, que, em termos mais teóricos, podem ser entendidos como os entes principais tratados em um discurso; processos - são os terms of action, as ações, as atividades relativas às coisas, que, teoricamente, podem ser vistos como aquilo que incide sobre o concreto, aquilo que é proferido a respeito do concreto (KAISER, 1911). Uma outra categoria, pode-se dizer, complementar, foi definida por Kaiser para melhor especificar os concretos dos assuntos - a categoria países, ou lugares. Segundo o criador do systematc indexing, normalmente os assuntos especializados se referem a algum commoditie (coisa, substância). As coisas podem ser divididas em móveis (como equipamento, mobília, pessoas), imóveis (como rio, montanha, terreno) e abstratas (como trabalho, inteligência, sentimento). Dentre as coisas imóveis, Kaiser deu especial atenção aos países, no sentido político e legislativo, ou seja, naqueles aspectos que dizem respeito aos habitantes, idiomas, costumes e leis. Assim, Kaiser estabeleceu outra classe de coisas expressas na literatura: os países.

Diante disso, definiram-se as categorias: concreto - país - processo, e a análise de assuntos, desse modo, passou a ser realizada por meio de categorias ontológicas previamente estabelecidas. A análise de assunto de um documento que tratasse, por exemplo, das taxas tributárias de exportação dos produtos agrícolas brasileiros poderia, a partir desse momento, ser realizada com base na identificação das categorias:

Concreto - Produto agrícola

Lugar - Brasil

Processo - Exportação

Um documento que abordasse questões relativas à oscilação do dólar nos EUA, poderia ser tratado em termos de: 
A importância de Julius Kaiser para a Organização do Conhecimento: um estudo comparativo com as perspectivas de Cutter, Otlet e Ranganathan

Concreto - Dólar

Lugar - EUA

Processo - Oscilação

Em um assunto que tratasse a respeito do comércio de petróleo na Venezuela, seriam extraídas as categorias:

Concreto - Petróleo

Lugar - Venezuela

Processo - Comércio

A análise categorizada de Kaiser, que, arrisca-se afirmar, é uma combinação da análise pautada em componentes informativos idealizada por ele e por Otlet, com o modo aristotélico de analisar proposições, foi o marco inicial da concepção 'analítica' do método analíticosintético retrabalhado, posteriormente, por Ranganathan.

A dimensão analítica desenvolvida por Ranganathan reflete toda preocupação e complexidade teóricas que sempre estiveram presentes em seu trabalho, enquanto bibliotecário e enquanto classificacionista. Sua abordagem, diferente da de Kaiser, cujas explicações metodológicas sempre tiveram um 'tom' mais de 'manual' a ser seguido, é fundamentada por um raciocínio teórico ‘declarado’ em suas inúmeras publicações. Aliás, suas obras e ideias estão constantemente presentes na literatura da organização do conhecimento, diferentemente das de Kaiser, cujas interpretações e comentários ainda não foram significativamente alavancadas ou, ao menos, destacadas pelos estudiosos da área.

Ranganathan buscou explicar o universo de assuntos a ser classificado de maneira bastante abrangente, partindo desde a percepção humana (por meio de perceptos), passando pela formação dos conceitos no campo cognitivo, pelos processos de apercepções, que dão, segundo Campos (2001), origem às ideias que, quando comunicadas, acumuladas e conservadas pela humanidade, formam juntas o universo do conhecimento. Quando parte deste conhecimento é organizada, sistematizada e aplicada à determinada área do saber, surgem os assuntos na concepção dinâmica de Ranganathan (CAMPOS, 2001).

Salvaguardado o fato de que o universo a ser analisado por Kaiser se distingue do de Ranganathan pelo escopo, o primeiro de escopo técnico e especializado, o segundo de escopo enciclopédico e universal, não é descabido afirmar que ambos desenvolveram suas dimensões analíticas com base nos elementos que compõem os assuntos contidos nos conteúdos dos documentos. A dimensão analítica de Ranganathan concentra-se nos elementos formadores dos assuntos complexos. Sua abordagem considera essencialmente dois elementos classificatórios,

InCID: R. Ci. Inf. e Doc., Ribeirão Preto, v. 7, n. 1, p. 43-65, mar./ago. 2016. 
o assunto básico e a ideia isolada. O assunto básico corresponde, na maioria das vezes, às áreas mais abrangentes do conhecimento, sem nenhuma ideia isolada que o complemente (CAMPOS, 2001). A ideia isolada corresponde a um componente de assunto, por si só não é um assunto, é um conceito (Idem). Em outras palavras, o passo inicial para a análise de um assunto é a identificação dos elementos de assuntos mais gerais e abrangentes (assuntos básicos) e dos elementos que os servem de complemento (ideias isoladas ou isolados).

Tanto as ideias básicas quanto as isoladas são tratadas com base em suas respectivas facetas, ou seja, são agrupadas por um termo genérico (a faceta) que é utilizado para a formação dos termos, e dos códigos, que representam os assuntos. Desse modo, as facetas que agrupam os assuntos básicos são as facetas básicas, e as que agrupam os isolados são as facetas isoladas. Cada campo específico de saber tende a possuir suas próprias facetas, ou seja, seus próprios aspectos particulares. Por exemplo, o campo da Literatura poderia possuir como facetas: gênero literário, autor, obra, editor etc. Entendendo facetas como aspectos particulares de campos específicos, verifica-se que Ranganathan desenvolveu uma análise de assunto com base no agrupamento (por facetas) dos termos (tanto gerais quanto específicos) identificados como fundamentais para a representação de um assunto composto.

Ranganathan, aprimorando seu método sistemático, definiu o princípio das categorias fundamentais: Personalidade (P), Matéria (M), Energia (E), Espaço (S) e Tempo (T), conhecido como PMEST. Esse princípio zelava pela ordem de citação de concretividade decrescente, e passou a ser empregado a partir da quarta edição da Colon Classification. Embora Ranganathan tenha utilizado as categorias PMEST também com a finalidade de suprir insuficiências relativas à síntese de seu sistema, observa-se que tais categorias têm, também, importância capital na dimensão analítica, visto que, o próprio Ranganathan (1976), referente ao plano ideacional, afirmava que cada faceta de qualquer assunto devia ser considerada como uma manifestação de uma das cinco categorias fundamentais: Personalidade (objeto estudado), Matéria (materiais e substâncias), Energia (ações e processos), Espaço (local) e Tempo (época). Tanto Kaiser quanto Ranganathan buscaram tecer suas análises de assuntos de modo a não ficarem restritos apenas aos assuntos dos documentos, mas, sim, aos aspectos fundamentais (categorias) do universo do conhecimento gerador dos assuntos. E nesse ponto, Ranganathan foi mais além, pois Kaiser generalizou que todos os assuntos técnico-especializados poderiam ser tratados com base em concretos e processos, ao passo que Ranganathan, para além das categorias fundamentais, aprofundou sua classificação de assuntos aos níveis das facetas (SALES; GUIMARÃES, 2014). 
A importância de Julius Kaiser para a Organização do Conhecimento: um estudo comparativo com as perspectivas de Cutter, Otlet e Ranganathan

Ranganathan definia que o universo de assunto deveria ser analisado do particular ao geral até se chegar às cinco ideias genéricas finais, indivisíveis e fundamentais. Essas ideias não possuíam valor de verdade ou falsidade, apenas de utilidade para fins de classificação. Portanto, não são definíveis, apenas supostas (RANGANATHAN, 1967). As facetas, para Ranganathan, estão presentes nos conteúdos dos documentos e não necessariamente no universo do conhecimento. O que de fato está no universo do conhecimento são as categorias. As facetas estão nos universos dos assuntos (SALES, 2014).

Nesse sentido, tomam-se exemplos utilizados anteriormente, que ilustraram as categorias de Kaiser, no intuído de visualiza-los também na perspectiva de Ranganathan, exclusivamente no nível das categorias, que é o nível que os aproxima - o nível dos princípios gerais.

No caso de um documento cujo assunto aborde as taxas de exportação dos produtos agrícolas no Brasil, pode-se vislumbrar a seguinte análise:

Personalidade $(\mathrm{P})$ - Produto agrícola

Energia (E) - Exportação

Espaço (S) - Brasil

Cabe ressaltar que, os termos Produto agrícola, Brasil e Exportação são componentes que formam um assunto complexo e, que, agrupados por facetas, são manifestações das categorias P, E e S, respectivamente, da mesma forma que na análise de assunto de Kaiser são manifestações das categorias Concreto, Lugar e Processo. Nota-se que; o termo Produto agrícola é um termo composto que combina um assunto básico (Agricultura) e uma ideia isolada (Produto). Sob a perspectiva de análise com base nas categorias PMEST, evidentemente, algumas informações a mais poderiam ser descritas. Por exemplo, se o documento abordasse de fato as taxas de exportação de produtos agrícolas no Brasil do século XX, a categoria referente ao aspecto temporal também se manifestaria na análise do assunto: Personalidade (P) - Produto agrícola; Energia (E) - Exportação; Espaço (S) - Brasil; Tempo (T) - Século XX.

Da mesma forma, o documento cujo assunto seja a oscilação do dólar nos EUA no ano de 2007, poderia ser analisado assim:

Personalidade (P) - Dólar

Energia (E) - Oscilação

Espaço (S) - EUA

Tempo (T) - 2007 
Rodrigo de Sales e José Augusto Chaves Guimarães

Observando os exemplos acima, nota-se uma correspondência entre as categorias: Concreto e Personalidade; Lugar e Espaço e; Processo e Energia. Por se tratarem de princípios gerais (maiores termos genéricos possíveis) e, como ressaltou Ranganathan (1967), por se tratarem de categorias fundamentais indefiníveis (pois são apenas supostas), a categorização não garante uma análise uniforme, isenta de variações. Mas, garante uma direção, uma forma de analisar. Independentemente das naturezas das categorias se diferenciarem quanto à perspectiva - categorias semânticas no caso de Kaiser (SVENONIUS, 2000), categorias ontológicas no caso de Ranganathan (ARANALDE, 2009) - o fato é que o pragmatismo (enquanto práxis que sistematizava seus respectivos métodos) utilizado por ambos ao desenvolverem as análises dos assuntos é semelhante: analisar discursos com base em seus elementos constituintes fundamentais, ou seja, analisar assuntos com base em categorias predeterminadas.

Essa forma de analisar, baseada na identificação de 'aspectos elementares' dos universos de conhecimentos e de assuntos, 'cristalizados por categorias', consiste na dimensão analítica do método analítico-sintético. Portanto, esse tipo de análise foi iniciado por Kaiser e continuado por Ranganathan, que por sua vez, avançou a especificidade analítica para o nível mais particular das facetas, adotando a ideia de termos mais gerais (facetas) servirem como dispositivos de agrupamentos de termos específicos, que serviriam como componentes de assuntos.

\section{As dimensões sintéticas de Kaiser e Ranganathan}

A dimensão sintética aqui apresentada está direcionada à compreensão de "como" Kaiser e Ranganathan uniram artificialmente seus assuntos decompostos em categorias, e não no julgamento da validade de suas declarações de assuntos. Discorrer a respeito das sínteses de Kaiser e de Ranganathan é direcionar a atenção aos caminhos por eles tomados quando procuraram solucionar a representação padronizada de suas análises de assunto, ou seja, direcionar o foco ao pragmatismo de ambos no que se refere à eficiência da construção das declarações de assuntos. Desse modo, analisam-se as 'reorganizações de informações de assuntos' promovidas pela indexação de Kaiser e pela classificação de Ranganathan. Vale ressaltar que, embora a síntese de Ranganathan esteja, em última instância, em suas codificações, o que por ora interessa é a forma como ele utilizou seus princípios mais genéricos (as categorias) para dar rumo à sua síntese.

InCID: R. Ci. Inf. e Doc., Ribeirão Preto, v. 7, n. 1, p. 43-65, mar./ago. 2016. 
A importância de Julius Kaiser para a Organização do Conhecimento: um estudo comparativo com as perspectivas de Cutter, Otlet e Ranganathan

Kaiser (1908; 1911) empregou o termo statement para designar a declaração ou cabeçalho de assunto de seu sistema. Os statements eram, essencialmente, expressões verbais padronizadas, compostas por termos que manifestavam as categorias concreto (e localidade) e processo, nos assuntos analisados. Em outras palavras, os statements consistiam na representação das informações mais relevantes extraídas dos assuntos dos documentos, tomando por base os "aspectos estáticos coisas - analisadas em nível de concretos) e os aspectos dinâmicos (aquilo que incide sobre as coisas - analisado em nível de processos)" (SALES; GUIMARÃES, 2014, p. 61). Assim, para o entendimento da dimensão sintética a atenção voltar-se-á ao modus operandi da construção dos índices, pontualmente no desenvolvimento dos statements, afinal, foi por meio deles que Kaiser procurou estabelecer como os assuntos analisados poderiam ser padronizadamente enunciados.

Para uma construção eficiente de índices de assuntos, era necessário decidir quais seriam as combinações possíveis entre essas informações trazidas pelas categorias, ou seja, fazia-se necessário ater-se, também, à questão da ordem de importância das categorias para estabelecer uma ordem de citação adequada aos enunciados. Para Kaiser, existiam três possíveis combinações: concreto - processo; país - processo e; concreto - país - processo.

Exemplo da combinação 1: Produto agrícola - Exportação

Exemplo da combinação 2: Brasil - Exportação

Exemplo da combinação 3: Produto agrícola - Brasil - Exportação

Verifica-se que a ordem de importância definida por Kaiser privilegia a concretividade dos aspectos dos assuntos, privilegia aquilo que é mais estático, aquilo que é 'coisificado' (no sentido ontológico do termo). Observa-se que a categoria concreto (quando existir no assunto) sempre estará em posição privilegiada se comparada com as categorias país (lugar) e processo.

Kaiser determinou em sua síntese a possibilidade de ampliações dos enunciados, de forma a viabilizar a inclusão de elementos não contemplados em um único enunciado de combinação padrão, conforme exposto acima. Para tanto, adotou o termo amplification para se referir a um suplemento do statement. Os tipos de amplificação definidos por Kaiser foram: a extensão do enunciado, as datas e os autores. Desse modo, Kaiser (1911, § 305) tabulou as partes de uma informação da seguinte maneira:

\footnotetext{
Statement: $\quad$ Concrete - Country - Process

Amplification: Extension - Dates - Authors
} 
Rodrigo de Sales e José Augusto Chaves Guimarães

Os elementos descritos acima foram conjuntamente denominados por Kaiser de index item (item do índice). Em outras palavras, tratava-se do item a ser utilizado para a indexação. Exemplo da síntese de Kaiser:

Informação do documento: Durante os últimos seis meses os preços pagos para o papel têm tido um aumento contínuo, devido a sua escassez. O mercado indiano está com seus estoques quase esgotados, dificultando a obtenção de grandes quantidades e, em alguns casos, os preços habituais têm avançado de 60 a 80 por cento.

Enunciado: $\quad$ Papel - Índia - Demanda

Amplificação/Extensão: Os preços têm avançado 60-80\% devido à escassez.

Adaptação (KAISER, 1911, § 307).

Nota-se que o registro das categorias complementado pela amplificação procura suprir possíveis insuficiências que sua análise, baseada nas categorias, poderia ter na representação de assuntos especializados. Delegando aos indexadores a função, ou a opção, de identificar informações secundárias relevantes, Kaiser antecipou uma forma de representação sintética de assuntos que respeitasse a dinamicidade e a expansividade dos conhecimentos especializados.

Inicialmente (nas três primeiras edições da Colon Classification), a síntese de Ranganathan era determinada por uma fórmula facetada que (pré)estruturava cada área de conhecimento. Por exemplo, imagina-se o assunto Solubilidade do Sódio. Recorrendo à Colon Clasification, verifica-se que: a classe de assunto Química é representada pela letra maiúscula $E$; o conceito Sódio é designado pelo código 111 e o conceito Solubilidade é denotado pelo código 2201. Assim, a síntese para Solubilidade do Sódio seria representada pela notação E111:2201. O assunto Solubilidade do Sódio seria assim representado pelo esquema rigidamente facetado porque a fórmula facetada para a área de Química determinava que os assuntos, a ela relacionada, deveriam ser representados nessa ordem: primeiro a Classe, depois a faceta que correspondesse à Personalidade (Sódio - 111), seguida das demais facetas, que respeitariam a ordem de concretividade decrescente (no exemplo, 2201- Solubilidade é a manifestação de uma Energia).

Essa estrutura prefixada pela fórmula facetada se assemelha à estrutura prefixada dos enunciados de Kaiser, não somente por definir a ordem de citação, mas, principalmente, por tal ordem ser determinada pela concretividade decrescente. Embora cada classe de assunto apresentasse uma fórmula própria, a orientação preconcebida para a combinação dos conceitos identificados na análise foi um aspecto preconizado por Kaiser. No entanto, Ranganathan avançou a questão da síntese de assuntos em prol de uma classificação de assuntos que efetivamente respeitasse a dinamicidade do conhecimento. Tentar prever a ordem mais 
A importância de Julius Kaiser para a Organização do Conhecimento: um estudo comparativo com as perspectivas de Cutter, Otlet e Ranganathan

adequada para a síntese dos assuntos não era uma maneira apropriada de acompanhar o caráter expansivo do universo do conhecimento. Assim, Ranganathan, rompendo com a rigidez de seu esquema classificatório, a partir da quarta edição da Colon Classification (1952), abandonou o princípio da fórmula facetada e, de certa forma, delegou a definição da ordem de importância dos conceitos na síntese aos utilizadores do sistema. A partir desse momento, o esquema de Ranganathan passou a ser considerado, por ele mesmo, como um esquema livremente facetado, ou analítico sintético, pois não determinava mais a ordem para a combinação dos conceitos (SALES, 2014; SALES; GUIMARÃES, 2014).

A combinação passou a ser conduzida por princípios, o que possibilitava a criação de novas subdivisões. No que se refere às atualizações dos conhecimentos e dos assuntos, Kaiser, embora não tenha avançado tanto nessa questão quanto Ranganathan, também não as negligenciou. Mesmo não abandonando as combinações predeterminadas das categorias que compunham os enunciados, Kaiser, por trabalhar com linguagem alfabética, flexibilizou a rigidez de sua síntese ao abrir espaço para as amplificações que complementavam os enunciados. Desse modo, peculiaridades características dos assuntos especializados, não contempladas pelas categorias, podiam ser incluídas na síntese dos assuntos. Nesse quesito, Ranganathan ampliou a flexibilidade de sua síntese não com elementos complementares, mas sim com aspectos estruturais, que deram maior liberdade à própria construção das notações.

Unindo as dimensões analítica e sintética desenvolvidas por Kaiser e Ranganathan, é possível destacar uma interlocução teórico-metodológica entre ambos os bibliotecários. Tanto Kaiser quanto Ranganathan realizaram suas análises por meio da decomposição dos assuntos em suas partes constituintes, transitando entre o plano ideacional, que define e ou supõe as categorias de análise e, o plano verbal, que dá os contornos terminológicos às ideias contidas nos assuntos. Para a realização da síntese, ambos reapresentam os assuntos por meio da recomposição dos mesmos pautada na construção de declarações de assuntos (verbal, no caso de Kaiser e, notacional, no caso de Ranganathan), cujas ordens de importância são orientadas pelo grau de concretividade que as categorias de análise apresentam (SALES, 2014).

Assim, verifica-se que, mesmo Kaiser apresentando como produto de seu método uma declaração verbal e Ranganathan uma declaração notacional, o fato é que ambos trataram seus contextos de organização temática da informação de maneira fundamentalmente semelhante. Como afirma Sales (2012; 2014), Kaiser fez surgir a construção de índices analítico-sintéticos e, posteriormente, Ranganathan fez surgir a construção de classificações analíticas-sintéticas. 


\section{Conclusões}

A presença de Kaiser no desenvolvimento teórico-metodológico da organização do conhecimento, entendendo organização do conhecimento como espaço investigativo e de atuação profissional, foi destacado neste artigo pontualmente na interlocução teórica e prática de Kaiser com alguns de seus contemporâneos. Ao colocar o trabalho desenvolvido por Kaiser lado a lado com as contribuições de Cutter, Otlet e Ranganathan, três expoentes nos estudos de organização do conhecimento, tornou-se possível verificar a importância daquele para o desenvolvimento do arcabouço teórico e metodológico da área, de especial maneira no que se refere à organização e ao tratamento temático da informação, vertente, esta, de significativa influência no pensamento ocidental anglo-americano.

A definição de regras e princípios para a elaboração de enunciados de assunto, uma interlocução entre Kaiser e Cutter, contribuiu fundamentalmente para o avanço teórico e prático das questões atinentes à catalogação de assuntos e à indexação, ou seja, aos estudos de catalogadores e indexadores de unidades de informação. De modo semelhante, porém com preocupações mais conceituais, a análise de assuntos baseada em componentes específicos de conteúdos de documentos para uma recuperação de informação mais especializada, postura que coloca Kaiser e Otlet em nítida convergência, contribuiu para o desenvolvimento teórico e metodológico tanto da classificação de assuntos complexos quanto da construção de instrumentos (enciclopédicos ou especializados) de organização e recuperação de informações.

Em uma perspectiva mais teórica, as bases pragmáticas da abordagem analíticosintética, baseada em categorias utilizadas tanto na análise quanto na síntese dos assuntos, interseção entre Kaiser e Ranganathan, influenciou tanto à classificação quanto à indexação do século XX. Nesses termos, colocar Kaiser no rol dos grandes expoentes da organização do conhecimento é mais do que uma justiça histórica, é uma responsabilidade epistemológica. 
A importância de Julius Kaiser para a Organização do Conhecimento: um estudo comparativo com as perspectivas de Cutter, Otlet e Ranganathan

\section{Referências}

ARANALDE, M. M. Reflexões sobre os esquemas categoriais de Aristóteles, Kant e Ranganathan. Ciência da Informação, Brasília, v. 38, n. 1, p. 86-108, jan./abr. 2009.

BARBOSA, A. P. Teoria e prática dos sistemas de classificação bibliográfica. Rio de Janeiro: Instituto Brasileiro de Bibliografia e Documentação, 1969. 441 p. (Obras Didáticas; $1)$.

CAMPOS, M. L. A. Linguagem documentária: teorias que fundamentam sua elaboração. Niterói: EdUFF, 2001.

CESARINO, M. A. N.; PINTO, M. C. M. F. Cabeçalho de assunto como linguagem de indexação. Revista da Escola de Biblioteconomia, Belo Horizonte, ano 7, set. 1978, n. 2, p. $268-88$

COATES, E. J. Subject catagues: headings and structure. London: The Library Association, 1988.

CUTTER, C. A. Rules for a dictionary catalog. 4. ed. Washington: Government Printing Office, 1904.

DOUSA, T. M. Facts and frameworks in Paul Otlet's and Julius Otto Kaiser's theories of knowledge organization. Bulletin of the American Society for Information Science and Technology, v. 36, n. 2, p. 19-25, dez./jan. 2010a.

Julius Otto Kaiser's systematic indexing: a study of its theoretical content in its historical context. 2010. Relatório de qualificação (Doutorado de 187 Philosophy in Library and Information Science) - Graduate College.University of Illinois. Urbana-Champaign, $2010 b$.

FOSKETT, A. C. A abordagem temática da informação. São Paulo: Polígono; Brasília: Ed.UnB, 1973.

The subject approach to information. 5. ed. London: Clive Bingley, 1986.

IMMROTH, J. P. Analysis of vocabulary control in L. C. Classification and Subject Headings. Littleton: Lib. Unlimited, 1971.

KAISER, J. O. Systematic indexing. London: Isaac Pitman \& Sons, 1911 (The Card System Series, 2). Disponível em:

$\langle$ http://www.archive.org/stream/systematicindexi00kaisuoft\#page/n0/mode/2up $>$. Acesso em: 28 jan. 2010.

The card system at the office. London: Vacher \& Sons, 1908. (The Card System Series, 1). Disponível em: 〈https://archive.org/details/cardindexsystemi00byleric >. Acesso em: 12 abr. 2011.

LANGRIDGE, D. W. Approach to classification: for studants of librarianship. London: Clive Bingley, 1973. 
Rodrigo de Sales e José Augusto Chaves Guimarães

MALTBY, A. Sayers' manual of classification for librarians. London: A. Deutsch, 1975

METCALFE, J. Subject classifying and indexing of libraries and literature. New York: Scarecrow, 1959.

MEY, E. S. A. Catalogação e descrição bibliográfica: contribuições a uma teoria. Brasília: Associação dos Bibliotecários do Distrito Federal, 1987.

Introdução à catalogação. Brasília: Briquet de Lemos, 1995.

MILLS, J. A morden outline of library classification. London, Chapman and Hall, 1960.

PIEDADE, M. A. R. Introdução à teoria da classificação. Rio de Janeiro: Interciência, 1977.

RANGANATHAN, S. R. Colon classification. 6. ed. Bombay; Calcutta; New Delhi; Madras; Lucknow; Bangalore; London; New York: Asia Publishing House, 1976.

Prolegomena to library classification. Bombay: Asia Publishing House, 1967.

SALES, R. A organização da informação de Julius Kaiser: o nascimento do método analítico-sintético. Saarbrücken, Alemanha: Novas Edições Acadêmicas, 2014.

A presença de Kaiser no quadro teórico do tratamento temático da informação (TTI). 2012. 190 f. Tese (Doutorado em Ciência da Informação) - Faculdade de Filosofia e Ciências, Universidade Estadual Paulista, Marília, 2012.

.; GUIMARÃES, J. A. C. O pragmatismo em Kaiser e Ranganathan e o pioneirismo na construção do método analítico-sintético. Scire, v. 20, n. 1, p. 53-64, jan./jun. 2014.

SHERA, J. H.; EGAN, M. E. Catálogo sistemático: princípios básicos e utilização. Brasília: Universidade de Brasília. 1969.

STRAIOTO, A. C.; GUIMARÃES, J. A. C. A abordagem facetada no contexto da organização do conhecimento: elementos históricos. Páginas a\&b (arquivos \& bibliotecas), Lisboa, n. 14, p. 109-136, 2004.

SVENONIUS, E. The intellectual foundation of information organization. Cambridge: MIT Press, 2000.

TAYLOR, A. G. On the subject of subjects. The Journal of Academic Librarianship, v. 21, n. 6, p. 484-491, nov. 1995.

TEIXEIRA, J. C. A. Cabeçalhos de assunto: manual para estudantes. Niterói: UFF, 1979. 